\title{
Visual Outcomes, Footplate Position and Vault Achieved with the Visian Implantable Collamer Lens for Myopic Astigmatism
}

\author{
Dan Z Reinstein $\mathbb{D}^{1-4}$ \\ Ryan S Vida' \\ Timothy J Archer (iD) \\ 'London Vision Clinic, London, UK; \\ ${ }^{2}$ Columbia University Medical Center, \\ New York, NY, USA; ${ }^{3}$ Sorbonne \\ Université, Paris, France; ${ }^{4}$ Biomedical \\ Science Research Institute, Ulster \\ University, Coleraine, UK
}

\begin{abstract}
Purpose: Report the outcomes of the implantable collamer lens (ICL) in myopic astigmatism using very high-frequency (VHF) digital ultrasound sizing.

Methods: Analysis of 42 consecutive ICL procedures using EVO and EVO+ (Visian V4c) lenses (STAAR Surgical) was done. ICL size was chosen using the ultrasound-based Kojima Formula with Insight 100 VHF digital ultrasound (VHFDU). Standard visual outcomes analysis was performed using 3-month data, also including contrast sensitivity, refractive and corneal vector analysis, and ECC. Postoperative lens position was evaluated using VHF digital ultrasound.

Results: Attempted SEQ was $-10.83 \pm 3.39 \mathrm{D}$ ( -4.40 to $-16.98 \mathrm{D})$. Cylinder was -1.46 $\pm 1.15 \mathrm{D}$ ( 0.00 to $-4.25 \mathrm{D})$. One-year follow-up was available in $86 \%$ of the eyes and 3 months in $96 \%$. Postoperative UDVA was $20 / 20$ or better in $89 \%$ of the eyes, relative to $71 \%$ preoperatively. Postoperative SEQ refraction was $\pm 0.50 \mathrm{D}$ in $74 \%$ and $\pm 1.00 \mathrm{D}$ in $98 \%$ of the eyes. There was a gain of one line of CDVA in $43 \%$ of the eyes, 2 or more lines in $10 \%$ of the eyes, while there was a one line loss in $7 \%$ and no eyes lost 2 or more lines. The vector mean for the corneal SIA was $0.24 \mathrm{D} \mathrm{Ax} 100$. Contrast sensitivity showed a statistically significant increase with a mean of $0.14 \log$ units at 6,12 , and 18 cycles per degree $(\mathrm{P}<0.01)$. The mean change in ECC was $-153 \pm 353$ cells $/ \mathrm{mm}^{2}$. Lens vault was 506 $\pm 233 \mu \mathrm{m}(114-924 \mu \mathrm{m})$. Footplate insertion was in zonular position in $48.3 \%$, ciliary body in $49.2 \%$, and sulcus in $2.5 \%$ of locations.
\end{abstract}

Conclusion: ICL implantation resulted in high safety and efficacy but with an implantation vault range that ideally would be improved upon. VHF digital ultrasound of the lens footplate and posterior anatomical relations may provide essential information for evaluating postoperative vault outliers.

Keywords: implantable collamer lens, ICL, phakic IOL, footplate, VHF digital ultrasound

\section{Introduction}

The V4c implantable collamer lens (ICL) (STAAR Surgical, Monrovia, CA) has been shown to provide effective subjective and objective visual outcomes with a low complication rate for a wide range of ametropia. ${ }^{1-5}$ The most important safety parameter is the lens separation, the distance between the ICL and the natural crystalline lens, commonly referred to as the vault. Low vault has been associated with early cataract formation, ${ }^{3,6}$ and high vault has been associated with increased IOP, pigment dispersion and glaucoma. ${ }^{7,8}$ The introduction of the "aquaport" central hole is considered to reduce the risk of postoperative cataract formation in ICLs with low vault, although this has not yet been reported in the long term. ${ }^{9}$
Correspondence: Dan Z Reinstein London Vision Clinic, 138 Harley Street, London, WIG 7LA, UK

Tel +44207224 1005

Fax +44 2072241055

Email dzr@londonvisionclinic.com 
The manufacturer recommended sizing algorithm for the ICL uses external anatomical landmarks to predict the fit of the ICL behind the iris. The manufacturer provides an online calculator, which requires data entry of the horizontal whiteto-white diameter (WTW), obtained by diagnostic devices or manual caliper measurements, ${ }^{10}$ plus the anterior chamber depth (ACD), keratometry and refraction. A number of reports demonstrate that ICL users may instead use internal measurements using optical coherence tomography (OCT) or analog ultrasound biomicroscopy in order to improve on the documented poor correlation between external ocular landmarks and internal posterior chamber anatomy and dimensions. ${ }^{11-17}$ Most notably, Dougherty et $\mathrm{al}^{11}$ and Kojima et a ${ }^{14}$ published sizing formulae based on handheld UBM measurements of posterior chamber dimensions, and Nakamura et al ${ }^{15,18}$ have developed a sizing formula derived from biometry by OCTbased anterior chamber (scleral-spur-to-scleral-spur) diameter and angle-to-angle lens rise. Both Dougherty and Kojima formulae employ the analog handheld UBM-based measurement of the posterior chamber sulcus-to-sulcus (STS). The Dougherty formula additionally includes the ICL power to be implanted while the Kojima additionally includes the ACD and sulcus-to-sulcus lens rise (STSL).

Handheld UBM devices provide imaging of the iris, including posterior pigmented epithelium, as well as structures behind the iris that are not visible by optical diagnostic devices, such as the sulcus, ciliary body, lens zonules, and the peripheral crystalline lens surface usually within scanning frequency ranges of about 25-35 MHz. The Artemis Insight 100 (ArcScan Inc, Golden, Colorado) very-high frequency (VHF) digital ultrasound scanner provides robotic scan control and includes infrared imaging of the eye during a reverse water-bath eye cup immersion scan for localization of much higher resolution B-scan images of the anterior segment including the anatomical landmarks of the posterior chamber using a short-pulse broadband $60 \mathrm{MHz}$ probe. ${ }^{16,19,20}$

The aim of the present study was to report comprehensive outcomes of treatments with the V4c EVO and EVO+ ICL with lens sizing based on Artemis Insight $100 \mathrm{VHF}$ digital ultrasound (VHFDU) scanning in combination with the Kojima formula derived from handheld-based scanning.

\section{Methods}

\section{Patients}

This was a retrospective analysis of consecutive ICL procedures for myopia or compound myopic astigmatism using the EVO and EVO+ (V4c) lens performed at the London Vision Clinic between April 2017 and January 2019 by a single surgeon (DZR). Informed consent and permission to use their data for general audit, analysis and anonymized publication was obtained from patients prior to surgery as part of the London Vision Clinic routine clinical care protocol. Being a retrospective study, an exemption from institutional review board approval was obtained from the United Kingdom Health Research Authority. The study complied with the tenets of the Declaration of Helsinki.

A full examination was performed by one of the inhouse optometrists. The full diagnostic testing protocol can be seen in Table 1. Manifest refraction was performed based on a standardized protocol to push maximum plus and maximum cylinder, and all optometrists had undergone refraction training and validation with this protocol. ${ }^{21}$ Patients who were found to be unsuitable for corneal refractive surgery were recommended phakic IOL surgery as an alternative vision correction option. The patient then returned for a second informed consent visit for further discussion and a repeat manifest refraction with the surgeon, which was used to order the ICL power through the manufacturer's Surgical Online Calculation $\&$ Ordering System $\left(\mathrm{OCOS}^{\mathrm{TM}}\right)$.

\section{Lens Sizing}

VHFDU scanning was performed in order to obtain anterior and posterior segment dimensions to be used for sizing. Iris registration image acquisition using the Verion Image Guided System (Alcon Laboratories, Inc., Fort Worth, TX) was performed for all eyes preoperatively regardless of astigmatism to ensure horizontal placement of the temporal main incision. The ICL size was chosen based on posterior chamber imaging by the Artemis Insight 100 VHFDU, operated by one of the clinic's technicians. An ICL preop scan set includes sweeps at $0,3,6,9,351,354$, and 357 degrees, for a total of 7 horizontal meridians. A minimum of 2 scans sets was required for every patient, providing at least 14 images to evaluate the horizontal biometry of the posterior chamber from which the 4 best images for each eye were used for biometry. All VHFDU scans were evaluated and analyzed by a single observer (RSV). Software calipers were used within the Insight 100 system to measure anterior chamber angle (ACA), ACD, STS, and STSL as can be seen in Figure 1.

The lens size recommended by the Dougherty ${ }^{11}$ sizing nomogram was derived using STS and lens power. The lens size recommended by the Kojima ${ }^{14}$ sizing nomogram 
Table I Diagnostic and Examination Schedule

\begin{tabular}{|c|c|c|c|c|c|c|}
\hline Examination & Pre-Op & I Day & I Week & I Month & 3 Months & 12 Months \\
\hline Subjective manifest refraction (CSV-1000) & $\mathbf{x}$ & $\mathbf{x}$ & $\mathbf{x}$ & $\mathbf{x}$ & $\mathbf{x}$ & $\mathbf{x}$ \\
\hline UDVA & $\mathbf{x}$ & $\mathbf{x}$ & $\mathbf{x}$ & $\mathbf{x}$ & $\mathbf{x}$ & $\mathbf{x}$ \\
\hline CDVA & $\mathbf{x}$ & & & $\mathbf{x}$ & $\mathbf{x}$ & $\mathbf{x}$ \\
\hline Cycloplegic refraction & $\mathbf{x}$ & & & & & \\
\hline Slit lamp examination & $\mathbf{x}$ & $\mathbf{x}$ & $\mathbf{x}$ & $\mathbf{x}$ & $\mathbf{x}$ & $\mathbf{x}$ \\
\hline Fundus examination & $\mathbf{x}$ & & & & & $\mathbf{x}$ \\
\hline Intraocular pressure (Goldmann) & $\mathbf{x}$ & & & & & $\mathbf{x}$ \\
\hline Contrast sensitivity (CSV-1000) & $\mathbf{x}$ & & & & $\mathbf{x}$ & $\mathbf{x}$ \\
\hline Ocular Response Analyzer intraocular pressure (ORA) & $\mathbf{x}$ & $\mathbf{x}$ & $\mathbf{x}$ & $\mathbf{x}$ & $\mathbf{x}$ & $\mathbf{x}$ \\
\hline Dark/Scotopic pupil diameter (Procyon) & $\mathbf{x}$ & & & & & \\
\hline Corneal topography (Atlas) & $\mathbf{x}$ & & & & $\mathbf{x}$ & $\mathbf{x}$ \\
\hline Corneal tomography (Pentacam) & $\mathbf{x}$ & & & & & \\
\hline Corneal tomography (MS-39) & $\mathbf{x}$ & & & $\mathbf{x}$ & $\mathbf{x}$ & $\mathbf{x}$ \\
\hline Anterior segment (MS-39) & $\mathbf{x}$ & $\mathbf{x}$ & $\mathbf{x}$ & $\mathbf{x}$ & $\mathbf{x}$ & $\mathbf{x}$ \\
\hline Wavefront (Osiris) & $\mathbf{x}$ & & & & & $\mathbf{x}$ \\
\hline Wavefront (WASCA) & $\mathbf{x}$ & & & & & \\
\hline Optical quality (HD Analyzer) & $\mathbf{x}$ & & & & $\mathbf{x}$ & $\mathbf{x}$ \\
\hline Endothelial cell count (SP-3000P) & $\mathbf{x}$ & & & & $\mathbf{x}$ & $\mathbf{x}$ \\
\hline Retinal OCT (RTVue) & $\mathbf{x}$ & & & & & $\mathbf{x}$ \\
\hline VHF digital ultrasound (Artemis Insight 100) & $\mathbf{x}$ & & & & $\mathbf{x}$ & $\mathbf{x}$ \\
\hline Quality of vision questionnaire (QoV) & $\mathbf{x}$ & & & & & $\mathbf{x}$ \\
\hline
\end{tabular}

Notes: CSV 1000 - Vector Vision, Greenville, OH. Procyon - Procyon Instruments Ltd, London, United Kingdom. Atlas - Carl Zeiss Meditec, Jena, Germany. Pentacam Oculus, Wetzlar, Germany. MS-39 - CSO, Florence, Italy. Osiris - CSO, Florence, Italy. WASCA - Carl Zeiss Meditec, Jena, Germany. HD Analyzer - Visiometrics, Costa Mesa, CA. ORA - Reichert Ophthalmic Instruments Inc., Buffalo, NY. SP-3000P - Topcon, Tokyo, Japan. RTVue - Optovue, Freemont, CA. Insight I00 - ArcScan Inc, Golden, CO.

was derived using STS, STSL, and ACD. The lens size recommended by the STAAR OCOS website was derived using WTW, lens power, and ACD. The lens size selected for surgery was based on the Kojima formula.

\section{Surgical Protocol}

The closest available lens power was chosen based on an age adjusted target postoperative hyperopic sphere, whereby the target spherical equivalent was $+0.66 \mathrm{D}$ for

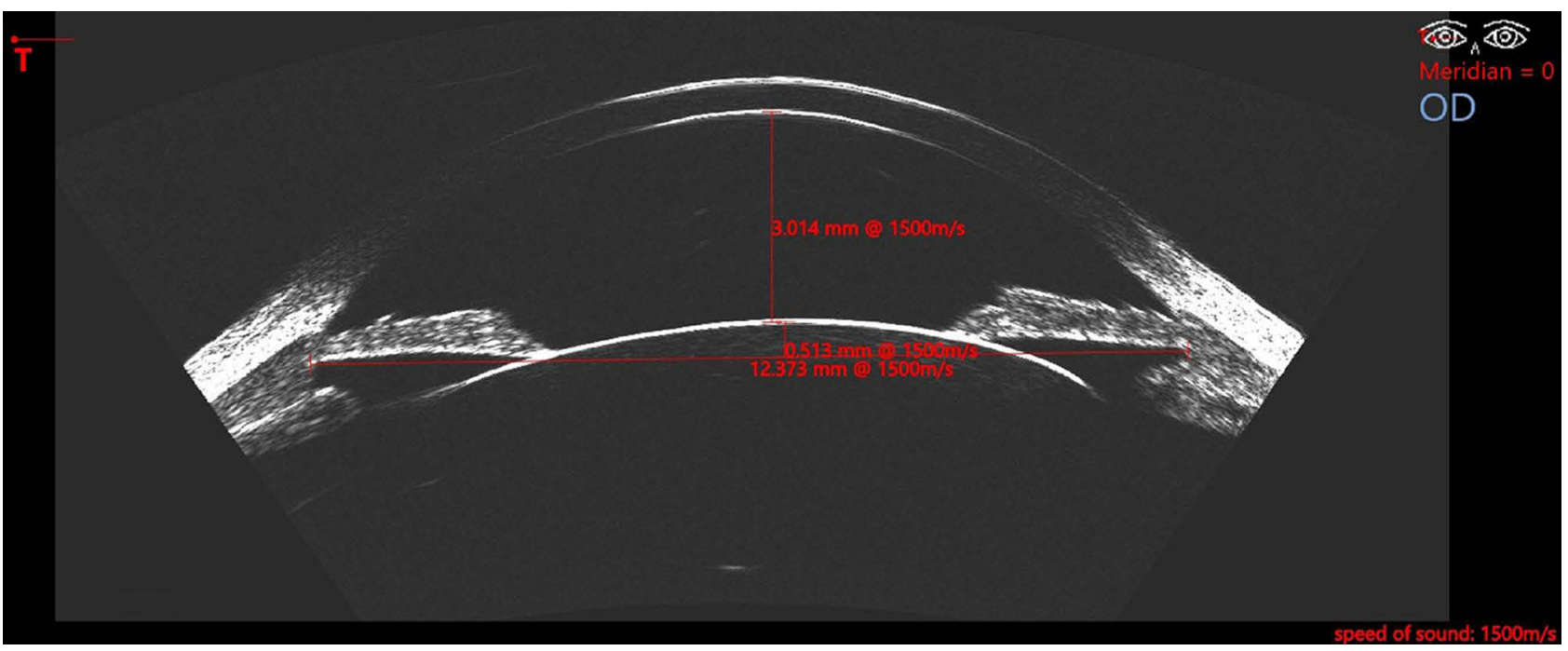

Figure I Ultrasound B-scan using the Insight 100 (ArcScan Inc, Golden, CO). Red caliper lines are shown measuring anterior chamber depth (ACD), sulcus-to-sulcus (STS), and crystalline lens rise from the sulcus plane (STSL). Other dimensions that can be measured from this scan include anterior chamber angle, angle-to-angle (ATA), ciliary body inner diameter (CBID), zonule-to-zonule (ZTZ), and crystalline lens rise from the zonular plane (ZTZL). 
a 21 year old, linearly decreasing to plano for a 42 year old. A micro-monovision protocol was used for patients older than 45 years, where the target sphere is plano for the dominant eye and a myopic power closest to -1.50 $\mathrm{D}$ for the non-dominant eye after appropriate preoperative tolerance testing. The EVO+ lens was used if available for the lens power required otherwise the EVO was used. All procedures were performed monocularly with a minimum of 2 days between the first (non-dominant) and second (dominant) eye. Peribulbar anaesthesia was used for all cases. Implantation was performed through a $3.2 \mathrm{~mm}$ temporal incision placed according to the Verion Image Guided System, which was also used to optimize astigmatic axis alignment intraoperatively. Mydriatics were used at the end of the procedure before leaving the operating room. An immediate postoperative examination 1 hour after surgery was performed to ensure adequate intraocular pressure and sutureless wound sealing.

\section{Postoperative Assessment}

Patients were instructed to wear plastic shields while sleeping for 7 nights. Tobramycin \& dexamethasone (Tobradex: Alcon, Fort Worth, TX, USA) and moxifloxacin (Moxivig: Novartis Pharmaceuticals UK Ltd, London, UK) were applied four times daily for the first week, and moxifloxacin continued for 3 weeks for broad spectrum prophylaxis. The surgeon reviewed the patient 1 day, and 3-5 days postoperatively and an in-house optometrist examined the patient at the 1-month, 3-month, and 12month visits. The complete set of postoperative tests and measurements performed is summarized in Table 1.

ICL central vault as well as ICL-induced anterior chamber angle dimensions were analyzed using OCT. Anterior chamber angle analysis was performed for the nasal and temporal angles (horizontal meridian). Lens haptic and footplate position was also evaluated using VHFDU. Change in endothelial cell count was performed using the SP-3000P specular microscope (Topcon, Tokyo, Japan).

\section{Statistical Analysis}

Outcome analysis was performed according to the Standard Graphs for Reporting Refractive Surgery including astigmatism. ${ }^{22}$ Postoperative data from the 1 -year visit was used for analysis if available, otherwise 3-month data were used. Eyes where the intended postoperative refraction was not emmetropia (partial correction patients) were excluded for the efficacy analysis (only). Vector analysis was performed for refractive cylinder as described by Alpins, ${ }^{23}$ with the cylinder axes reflected in the vertical meridian for left eyes. Stability analysis was performed for spherical equivalent refraction and refractive cylinder, and for MS39 (CSO Italia, Florence, Italy) mean simulated keratometry and corneal astigmatism. Vector analysis was also performed for corneal astigmatism using the Alpins ISRS calculator (www.isrs.org/resources/assortgroup-analysis-calculator) to evaluate the surgically induced astigmatism from the corneal incisions. Student's t-tests were used to calculate the statistical significance of any changes in log contrast sensitivity. Microsoft Excel 2010 (Microsoft Corporation, Seattle, WA, USA) was used for data entry and statistical analysis. A p-value $<0.05$ was defined as statistically significant.

\section{Results}

During the study period, 42 eyes of 21 patients met the inclusion criteria for analysis. Last follow-up was 12 months for 36 eyes (86\%), 3 months for 4 eyes $(10 \%)$, and 1 month for 2 eyes (5\%). Table 2 shows the demographic data for the study population, which included a wide range of age, spherical equivalent refraction and cylinder.

In the study population, 32 eyes $(76 \%)$ had a cornea classified as normal, 4 eyes (10\%) as forme fruste keratoconus (FFKC), which was defined as having corneal changes associated with early keratoconus but no loss in

Table 2 Population Demographics

\begin{tabular}{|l|c|}
\hline Eyes (patients) & 42 (2I patients) \\
\hline Age (years) & $31 \pm 6(24$ to 47$)$ \\
\hline Gender (M/F \%, n) & $48 \%(20) / 52 \%(22)$ \\
\hline $\begin{array}{l}\text { Attempted maximum myopic } \\
\text { meridian (D) }\end{array}$ & $-11.59 \pm 3.47(-5.93$ to $-17.8 \mathrm{I})$ \\
\hline $\begin{array}{l}\text { Attempted spherical equivalent } \\
\text { refraction (D) }\end{array}$ & $-10.86 \pm 3.37(-4.40$ to -16.98$)$ \\
\hline Attempted refractive cylinder (D) & $-1.45 \pm 1.15(0.00$ to -4.25$)$ \\
\hline Dark pupil diameter (mm) & $6.64 \pm 0.87(4.80$ to 8.44$)$ \\
\hline Scotopic pupil diameter (mm) & $5.55 \pm 0.90(3.44$ to 6.77$)$ \\
\hline Normal topography $(\%, n)$ & $71 \%(30)$ \\
\hline FFKC topography (\%, $n)$ & $14 \%(6)$ \\
\hline KC topography (\%, $n)$ & $14 \%(6)$ \\
\hline
\end{tabular}

Abbreviations: FFKC, forme fruste keratoconus; KC, keratoconus. 
Table 3 ICL Parameters and Anterior Chamber Dimensions

\begin{tabular}{|c|c|}
\hline ICL maximum myopia power (D) & $-12.31 \pm 3.06(-7.00$ to -17.50$)$ \\
\hline ICL cylinder power (D) & $1.35 \pm 1.13(0.00$ to 4.50$)$ \\
\hline ICL size: $12.6 \mathrm{~mm} / \mathrm{I} 3.2 \mathrm{~mm}(\%, \mathrm{n})$ & $52 \%(20) / 48 \%(22)$ \\
\hline ICL model: EVO/EVO+ $(\%, n)$ & $26 \%(\mathrm{II}) / 74 \%(3 \mathrm{I})$ \\
\hline Primary/backup lens used $(\%, n)$ & $98 \%(4 I) / 2 \%(I)$ \\
\hline $\begin{array}{l}\text { White-to-white horizontal } \\
\text { diameter }(\mathrm{mm})\end{array}$ & $11.75 \pm 0.34$ (11.12 to 12.49$)$ \\
\hline $\begin{array}{l}\text { Sulcus-to-sulcus horizontal } \\
\text { diameter }(\mathrm{mm})\end{array}$ & $11.93 \pm 0.43$ (11.22 to 12.70$)$ \\
\hline Anterior chamber depth $(\mathrm{mm})$ & $3.02 \pm 0.31$ ( 2.56 to 3.69$)$ \\
\hline $\begin{array}{l}\text { Crystalline lens rise from sulcus } \\
\text { plane }(\mu \mathrm{m})\end{array}$ & $0.57 \pm 0.19(0.10$ to 0.89$)$ \\
\hline ICL central vault at I month $(\mu \mathrm{m})$ & $506 \pm 233$ (II4 to 924$)$ \\
\hline Anterior chamber angle preop $\left({ }^{\circ}\right)$ & $42 \pm 7(28$ to 65$)$ \\
\hline $\begin{array}{l}\text { Anterior chamber angle at I } \\
\text { month }\left({ }^{\circ}\right)\end{array}$ & $24 \pm 4$ (14 to 36$)$ \\
\hline
\end{tabular}

CDVA, and 6 eyes (14\%) classified as mild-to-moderate keratoconus $(\mathrm{KC})$, which was defined as having corneal changes as well as a decrease in CDVA (Table 2).

Table 3 shows the lens parameters and the preoperative anterior and posterior chamber dimensions for the population. The $12.6 \mathrm{~mm}$ lens was used in 20 eyes $(52 \%)$ and a $13.2 \mathrm{~mm}$ lens was used in 22 eyes $(48 \%)$. The EVO+ lens was used in 31 eyes (74\%).

\section{Refractive and Visual Outcomes}

Figure 2 shows the Standard Graphs for Reporting Refractive Surgery. Postoperative UDVA was $20 / 20$ or better in $89 \%$ of the eyes, relative to $71 \%$ with preoperative CDVA of $20 / 20$ or better. Spherical equivalent accuracy was within \pm 0.50 $\mathrm{D}$ in $74 \%$ and within $\pm 1.00 \mathrm{D}$ in $98 \%$ of the eyes. There was a gain of line of CDVA in $43 \%$ of the eyes, 2 or more lines in $10 \%$ of the eyes, while there was 1 line loss in $7 \%$ and no eyes lost 2 or more lines.

\section{Refractive and Corneal Stability}

Table 4 shows spherical equivalent refraction, refractive cylinder, and MS39 average keratometry and corneal astigmatism before surgery and change between 3 and 12 months after surgery. As also shown in Table 4, the mean spherical equivalent refraction was $-0.07 \pm 0.30 \mathrm{D}$ at 3 months and
$-0.19 \pm 0.36 \mathrm{D}$ at 1 year, a mean change of $-0.12 \mathrm{D}$, although this was not statistically significant $(P=0.063)$. This change was not due to corneal changes as the average keratometry remained stable between 3 and 12 months $(P=0.523)$.

\section{Vector Analysis for Refractive Cylinder and Corneal Astigmatism}

Figure 3 shows the refractive cylinder vector analysis for eyes in which toric lenses were implanted and the main outcome measures are shown in Table 5. The scatter plot for surgically induced astigmatism vector (SIA) vs target induced astigmatism vector (TIA) shows that the refractive cylinder correction was on target in terms of magnitude. The angle of error histogram shows that the refractive correction was placed accurately on the intended meridian for the majority of eyes with $97 \%$ within $\pm 15^{\circ}$.

Figure 4 shows the vector analysis for corneal astigmatism. The vector mean for the corneal SIA was 0.24 D Ax 100 with an arithmetic mean of $0.35 \mathrm{D}$. This was associated with an induced change of $+0.15 \mathrm{D}$ in corneal astigmatism magnitude $(P=0.413)$ as shown in Table 5 . The corneal astigmatism was stable between 3 and 12 months $(P=0.732)$, showing no further change after the initial surgically induced change. Sub-group analysis of the eyes in which spherical lenses were implanted found a similar arithmetic mean of $0.39 \mathrm{D}$, but the vector mean was $0.08 \mathrm{D}$ Ax 123.

\section{Contrast Sensitivity}

Table 6 includes the mesopic contrast sensitivity data before and after surgery showing that there was a statistically significant increase with a mean of $0.14 \log$ units (equivalent to one patch on the CSV-1000) at 6,12 , and 18 cycles per degree $(P<0.01)$. The small increase of $0.04 \log$ units at 3 cycles per degree was not statistically significant $(P=0.287)$. Contrast sensitivity was decreased by more than $0.25 \log$ units in only 2 eyes (5\%) for each frequency.

\section{Lens Vault and Position}

Mean \pm SD lens vault at the 1-month time point was 506 $\pm 233 \mu \mathrm{m}$ (range: 114-924 $\mu \mathrm{m}$ ) as measured by MS-39 OCT. No lens justified an early ICL exchange procedure due to over- or under-sizing. A sub-analysis of the ICL footplate positioning was performed for the 30 eyes (71\%) where VHFDU scans were available at 3 months. The position of all 4 footplates were evaluated in each patient (120 footplates for 30 eyes). In this subgroup, the footplate 

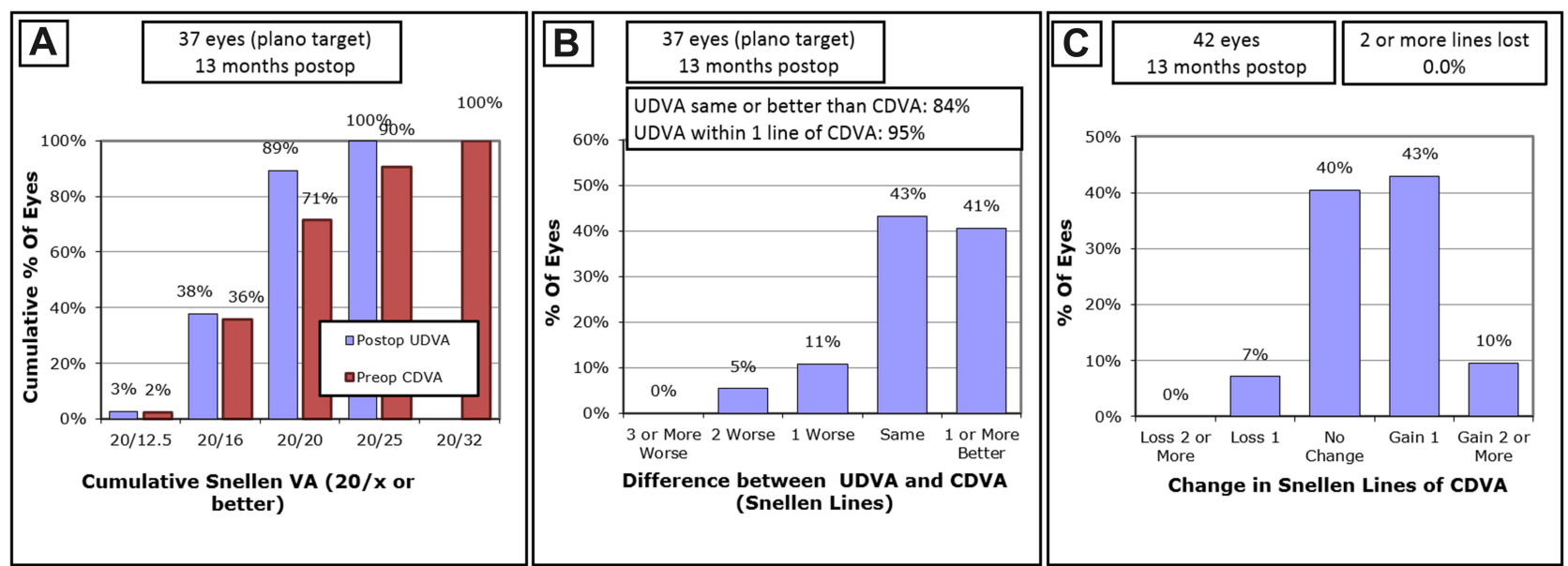

Uncorrected Distance Visual Acuity

Uncorrected Distance Visual Acuity Change in Corrected Distance Visual vs. Corrected Distance Visual Acuity Acuity

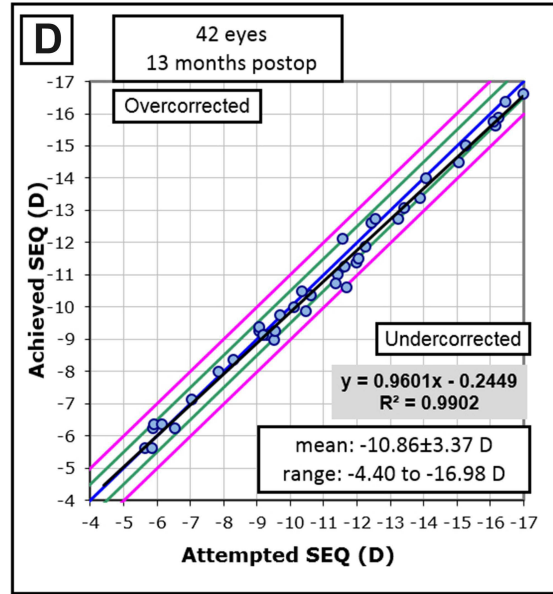

Spherical Equivalent Refraction Attempted vs Achieved

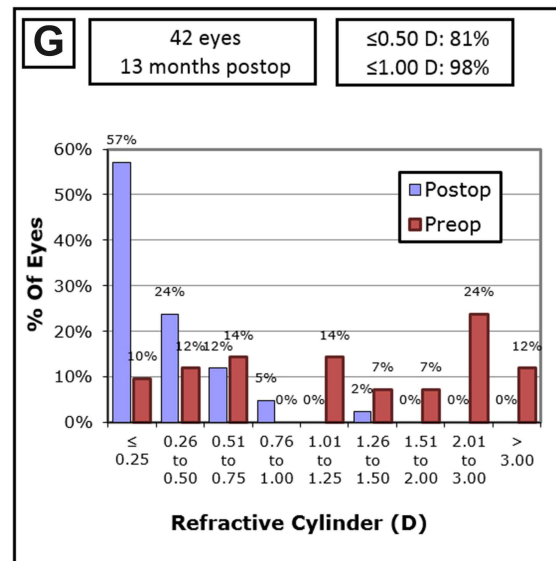

Refractive Cylinder

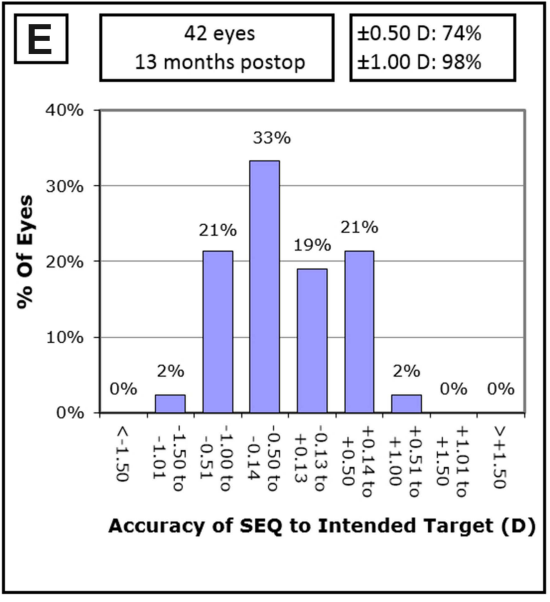

Spherical Equivalent Refraction Accuracy

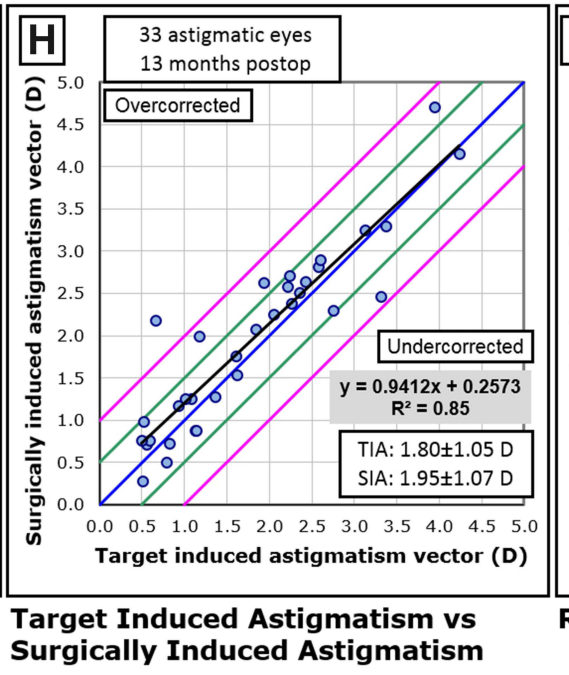

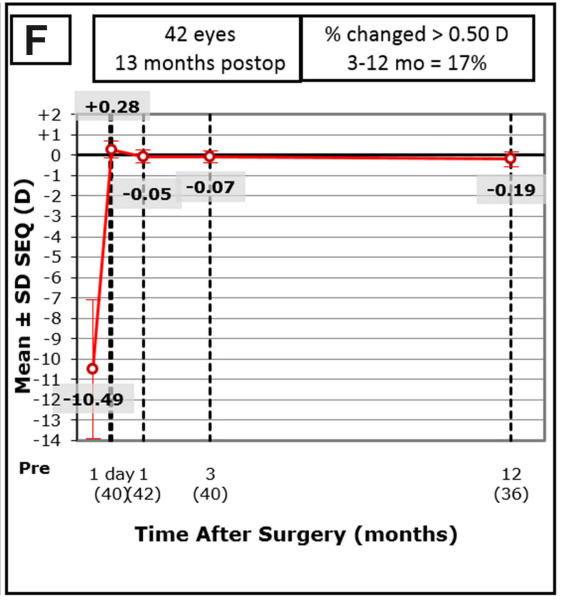

Spherical Equivalent Refraction Stability

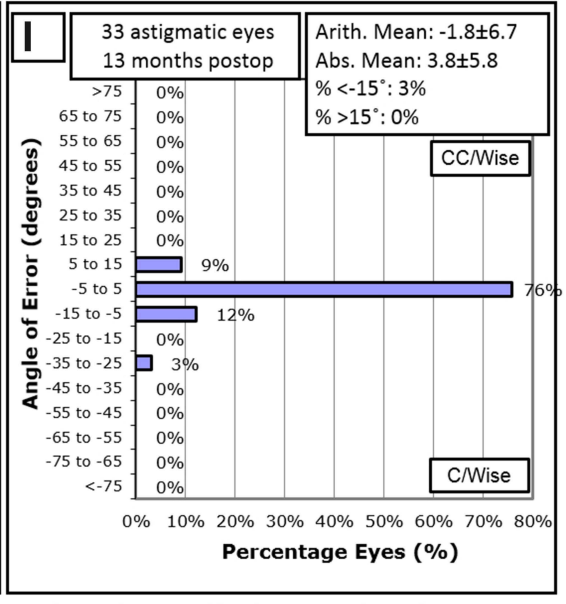

Refractive Cylinder Angle of Error

Figure 2 Nine standard graphs for reporting refractive surgery showing the visual and refractive outcomes for 42 phakic IOL treatments using the Visian V4c implantable collamer lens (Staar Surgical, Monrovia, CA)

Abbreviations: UDVA, uncorrected distance visual acuity; CDVA, corrected distance visual acuity; D, diopters; Postop, postoperative; Preop, preoperative; SEQ, spherical equivalent refraction; TIA, target induced astigmatism; SIA, surgically induced astigmatism. 
Table 4 Stability of Spherical Equivalent Refraction and SimK Keratometry

\begin{tabular}{|c|c|c|c|c|c|c|c|}
\hline & Preoperative & 3 Months & $\begin{array}{c}12 \\
\text { Months }\end{array}$ & $\begin{array}{l}\text { Pre-post } \\
\text { Change* }\end{array}$ & $\begin{array}{c}\text { Pre-Post } \\
\text { Change Within } \\
\pm 0.50 \mathrm{D}\end{array}$ & $\begin{array}{c}\text { 3-12 } \\
\text { Months } \\
\text { Change }\end{array}$ & $\begin{array}{c}\text { 3-12 Months } \\
\text { Change Within } \\
\pm 0.50 \mathrm{D}\end{array}$ \\
\hline Eyes with refraction & 42 & 40 & 36 & 42 & 42 & 36 & 36 \\
\hline $\begin{array}{l}\text { Spherical equivalent } \\
\text { refraction adjusted for } \\
\text { intended target }(D)\end{array}$ & $\begin{array}{c}-10.86 \pm 3.37 \\
(-4.40 \text { to } \\
-16.98)\end{array}$ & $\begin{array}{c}-0.07 \pm 0.30 \\
(-0.77 \text { to } \\
+0.59)\end{array}$ & $\begin{array}{c}-0.19 \pm 0.36 \\
(-1.07 \text { to } \\
+0.55)\end{array}$ & $\begin{array}{c}-10.67 \\
\pm 3.25 \\
(-16.63 \text { to } \\
-3.88)\end{array}$ & - & $\begin{array}{c}-0.12 \pm 0.38 \\
(-1.00 \text { to } \\
+0.63) \\
P=0.063\end{array}$ & $83 \%$ \\
\hline $\begin{array}{l}\text { Refractive cylinder } \\
\text { magnitude (D) }\end{array}$ & $\begin{array}{c}-1.45 \pm 1.15 \\
(0.00 \text { to }-4.25)\end{array}$ & $\begin{array}{c}-0.39 \pm 0.30 \\
(0.00 \text { to } \\
-1.25)\end{array}$ & $\begin{array}{c}-0.38 \pm 0.35 \\
(0.00 \text { to } \\
-1.50)\end{array}$ & $\begin{array}{c}-1.27 \pm 1.17 \\
(-4.00 \text { to } \\
+0.75)\end{array}$ & - & $\begin{array}{c}+0.03 \pm 0.24 \\
(-0.50 \text { to } \\
+0.50) \\
P=0.392\end{array}$ & $100 \%$ \\
\hline Eyes with topography & 42 & 40 & 36 & 42 & 42 & 36 & 36 \\
\hline Average keratometry (D) & $\begin{array}{c}44.61 \pm 1.45 \\
(42.28 \text { to } \\
48.01)\end{array}$ & $\begin{array}{c}44.64 \pm 1.49 \\
(42.12 \text { to } \\
47.63)\end{array}$ & $\begin{array}{c}44.59 \pm 1.44 \\
(42.17 \text { to } \\
47.58)\end{array}$ & $\begin{array}{c}-0.03 \pm 0.21 \\
(-0.67 \text { to } \\
+0.30) \\
P=0.413\end{array}$ & $98 \%(4 I)$ & $\begin{array}{c}-0.0 I \pm 0.1 I \\
(-0.27 \text { to } \\
+0.14) \\
P=0.523\end{array}$ & $100 \%$ \\
\hline $\begin{array}{l}\text { Corneal astigmatism } \\
\text { magnitude (D) }\end{array}$ & $\begin{array}{c}1.24 \pm 0.66 \\
(0.19 \text { to } 3.19)\end{array}$ & $\begin{array}{c}1.38 \pm 0.78 \\
(0.18 \text { to } \\
3.41)\end{array}$ & $\begin{array}{c}1.50 \pm 0.74 \\
(0.33 \text { to } \\
3.53)\end{array}$ & $\begin{array}{c}+0.15 \pm 0.28 \\
(-0.35 \text { to } \\
+0.69) \\
P=0.001\end{array}$ & $86 \%(36)$ & $\begin{array}{c}+0.01 \pm 0.21 \\
(-0.45 \text { to } \\
+0.37) \\
P=0.732\end{array}$ & $100 \%$ \\
\hline
\end{tabular}

Notes: *Using the last appointment, 12 months if available, 3 months otherwise.

positioned just anterior to the zonules flexing up toward the sulcus (zonule position) in 58 locations (48.3\%), inserted into the ciliary body (ciliary body insertion) in 59 locations (49.2\%), and inserted directly into the sulcus (sulcus position) in 3 locations (2.5\%). VHFDU enabled us to ensure that in the physiological state, there was no contact between the ICL and the crystalline lens in any eye, including for very high myopic ICL lenses where the thickest ICL portion is in the mid-periphery behind the iris and thus invisible to OCT B-scan imaging. An example of the different footplate positions can be seen in Figure 5.

\section{Anterior Chamber Angle}

Pre- and postoperative anterior chamber angle analysis was performed using OCT. The analysis was performed at $0^{\circ}$ and $180^{\circ}$. Preoperative mean angle was $42 \pm 7^{\circ}$ (range: $28-65^{\circ}$ ). The 1-month postoperative mean angle was $24 \pm 4^{\circ}$ (range: $12-29^{\circ}$ ).

\section{Endothelial Cell Count}

Table 7 includes the ECC data before and after surgery showing a mean change of $-153 \pm 353$ cells $/ \mathrm{mm}^{2}$ (range: -1238 to
639 cells $\left./ \mathrm{mm}^{2}\right)$, which was statistically significant $(P=0.014)$. Out of the 36 eyes with ECC data available both before and after surgery, there was a decrease in the measured endothelial density of more than 500 cells $/ \mathrm{mm}^{2}$ in 5 eyes $(14 \%)$ and a decrease of more than 1000 cells $/ \mathrm{mm}^{2}$ in 2 eyes (5\%). The postoperative ECC was greater than $2100 \mathrm{cells} / \mathrm{mm}^{2}$ for all eyes except for the 2 eyes with a loss of more than 1000 cells/ $\mathrm{mm}^{2}$. The ECC was stable from 3 to 12 months $(P=0.290)$.

One of the eyes measured as losing more than 1000 cells $/ \mathrm{mm}^{2}$ had undergone a lens exchange 1 month after the first treatment, exchanging an EVO for an $\mathrm{EVO}+$ lens (larger optic) as described fully below. The second eye that lost more than 1000 cells $/ \mathrm{mm}^{2}$ underwent a full case review with an in-depth review of the surgical video. The fit of the injector through the main incision was very tight and required a higher amount of manipulation. However, the remainder of the treatment was routine, including lens injection and placement.

\section{Complications}

A backup lens was used in 1 eye due to capture and tear of the trailing footplate within the loading cartridge while the ICL 

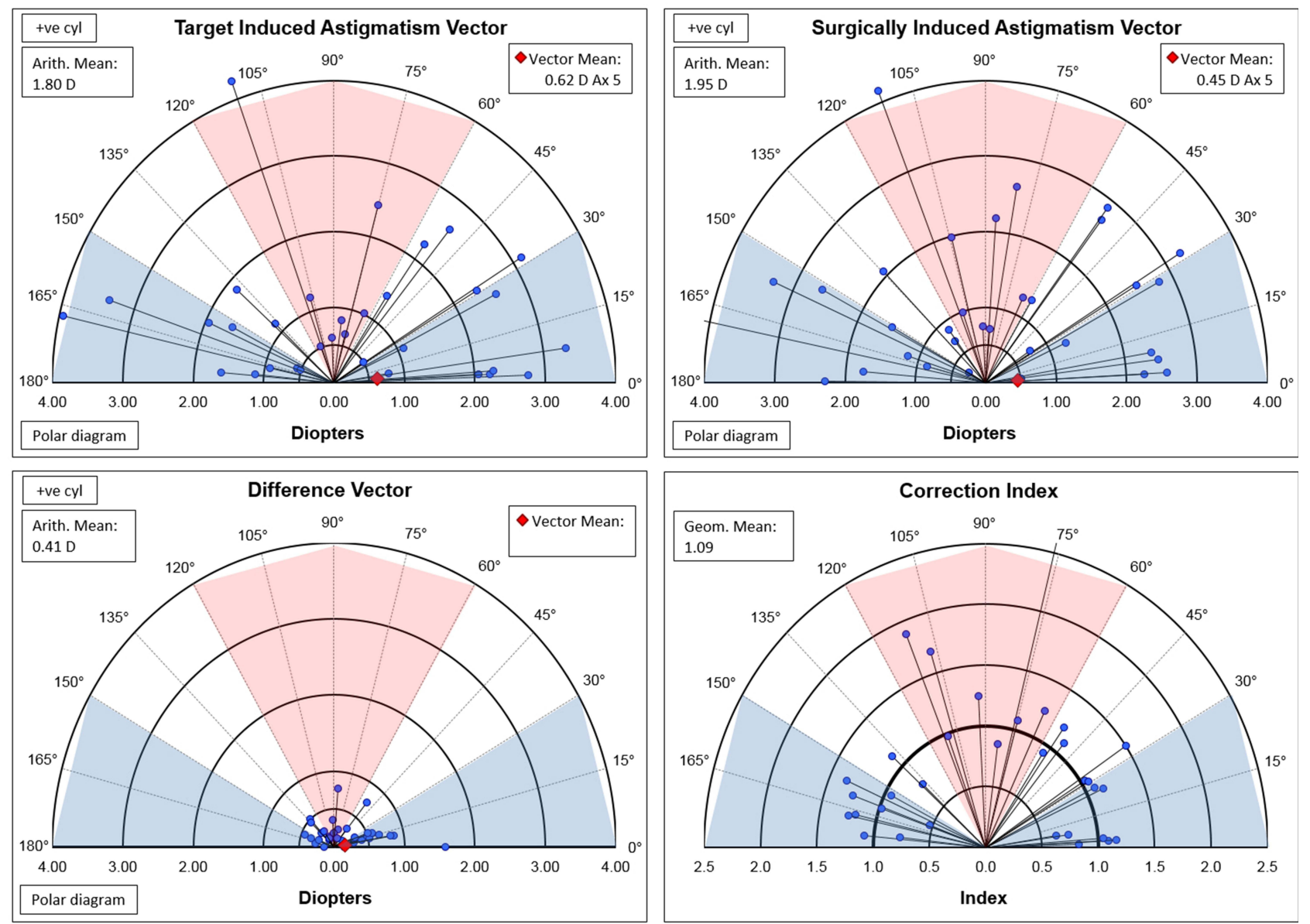

Figure 3 Vector analysis of refractive cylinder displayed as polar plots for target induced astigmatism vector (TIA), surgically induced astigmatism vector (SIA), difference vector (DV), and correction index (Cl).

was being injected. The ICL was removed from the cartridge, the backup lens was loaded, and surgery proceeded without complications.

A lens exchange procedure was performed for the first eye of a patient complaining of significant night vision glare in dim lighting conditions postoperatively. The glare was alleviated by brimonidine $0.1 \%$ drops but after counseling and discussion, the patient elected to have the ICL exchanged at 6 weeks postop from the EVO to EVO+ (of the same lens size). The second eye was implanted with an $\mathrm{EVO}+6$ weeks later without complications.

During the 12-month postoperative course, 4 eyes (in 3 patients) experienced mild anterior uveitis at the 1-month visit. In two of these eyes (one patient), there was also an IOP increase (42 $\mathrm{mmHg}$ in the right eye, $34 \mathrm{mmHg}$ in the left eye). The pressure increase was managed appropriately and re-checked for normalcy and stability. The patient requiring ICL exchange from EVO to EVO+ preferred to use diluted pilocarpine $(0.5 \%)$ eye drops on an as-needed basis to decrease halo at night in certain situations due to negative dysphotopsia.

\section{Discussion}

In the present study, we found the refractive and visual outcomes to be accurate and safe, particularly considering the high degree of myopia corrected (spherical equivalent refraction up to $-16.98 \mathrm{D}$ ), the relatively reduced preoperative CDVA, and the inclusion of forme fruste and keratoconus patients. Overall, for eyes targeted for emmetropia, UDVA was $20 / 20$ or better in $25 \%$ more eyes postoperatively than the $71 \%$ with $20 / 20$ or better spectacle CDVA preoperatively. Spherical equivalent refraction was within $\pm 0.50 \mathrm{D}$ in $74 \%$ and within $\pm 1.00 \mathrm{D}$ in $98 \%$ of the eyes. These refractive and visual outcomes were similar to previously published series. ${ }^{24-28}$

Endothelial cell count density reduction after ICL implantation is well documented, without clinically 
Table 5 Vector Analysis of Refractive Cylinder and Corneal Astigmatism

\begin{tabular}{|c|c|c|c|}
\hline & Toric Lenses & Spherical Lenses & Corneal Astigmatism \\
\hline Eyes & 33 & 9 & 42 \\
\hline $\begin{array}{l}\text { Target induced astigmatism vector (D) } \\
\text { Arithmetic mean } \\
\text { Summated vector mean }\end{array}$ & $\begin{array}{c}1.80 \pm 1.05 \\
(0.50 \text { to } 4.25) \\
0.62 \mathrm{~A} \times 5\end{array}$ & - & - \\
\hline $\begin{array}{l}\text { Surgically induced astigmatism vector (D) } \\
\text { Arithmetic mean } \\
\text { Summated vector mean }\end{array}$ & $\begin{array}{c}1.95 \pm 1.07 \\
(0.27 \text { to } 4.70) \\
0.45 \mathrm{~A} \times 5\end{array}$ & $\begin{array}{c}0.39 \pm 0.25 \\
(0.22 \text { to } 0.99) \\
0.08 \mathrm{Ax} 123\end{array}$ & $\begin{array}{c}0.35 \pm 0.19 \\
(0.04 \text { to } 0.70) \\
0.24 \mathrm{Ax} 100\end{array}$ \\
\hline Correction index - geometric mean & $1.09(0.53$ to 3.31$)$ & - & - \\
\hline $\begin{array}{l}\text { Difference vector }(D) \\
\text { Arithmetic mean } \\
\text { Summated vector mean }\end{array}$ & $\begin{array}{c}0.41 \pm 0.30 \\
(0.12 \text { to } 1.58) \\
0.16 \mathrm{Ax} 8\end{array}$ & $\begin{array}{c}0.39 \pm 0.25 \\
(0.22 \text { to } 0.99) \\
0.08 \mathrm{Ax} 33\end{array}$ & - \\
\hline Index of success - geometric mean & 0.22 (0.04 to 2.39$)$ & - & - \\
\hline $\begin{array}{l}\text { Angle of error }\left({ }^{\circ}\right) \\
\text { Arithmetic mean } \\
\text { Absolute mean }\end{array}$ & $\begin{array}{c}-1.8 \pm 6.7 \\
3.8 \pm 5.8\end{array}$ & - & - \\
\hline $\begin{array}{l}\text { Postop cylinder magnitude } \leq 0.25 D^{*} \\
\text { Postop cylinder magnitude } \leq 0.50 D^{*} \\
\text { Postop cylinder magnitude } \leq 1.00 D^{*} \\
\text { Postop cylinder magnitude } \leq 2.00 D^{*} \\
\text { Cylinder induced/SIA corneal astigmatism } \geq 0.50 \mathrm{D} \\
\text { Cylinder induced/SIA corneal astigmatism } \geq 1.00 \mathrm{D} \\
\text { Cylinder induced/SIA corneal astigmatism } \geq 2.00 \mathrm{D}\end{array}$ & $\begin{array}{l}52 \%(17) \\
76 \%(25) \\
97 \%(32) \\
100 \%(33) \\
3 \%(1) \\
0 \%(0) \\
0 \%(0)\end{array}$ & $\begin{array}{l}78 \%(7) \\
100 \%(9) \\
100 \%(9) \\
100 \%(9) \\
0 \%(0) \\
0 \%(0) \\
0 \%(0)\end{array}$ & $\begin{array}{c}- \\
- \\
- \\
- \\
24 \%(10) \\
0 \%(0) \\
0 \%(0)\end{array}$ \\
\hline
\end{tabular}

Note: *Relative to zero cylinder, rather than adjusted for ICL calculated target cylinder.

significant change both in the short and long term. ${ }^{29-31}$ The ECC analysis for the current population shows a similar finding with a mean change of $-153 \pm 353$ (range: -1238 to 639 ) over a 1 -year period. Of the two eyes in which there was a loss of more than 1000 cells/ $\mathrm{mm}^{2}$, one eye had undergone a lens exchange at 6 weeks, while another was thought to be related to a tighter ICL injector fit. There are no publications to date describing the impact of an ICL exchange procedure on endothelial cell count. This is an area that could do with further investigation and publication.

Anterior chamber analysis showed the expected decrease in anterior chamber angle between the preoperative and 1-month postoperative visit. The preoperative mean angle was $42^{\circ}$ while the postoperative mean was $24^{\circ}$. This is similar to $\mathrm{Li}$ et $\mathrm{al},{ }^{32}$ who reported a mean preoperative angle of $47.37^{\circ}$ ( 3 o'clock position) and postoperative angle of $27.56^{\circ}$ in 147 eyes. Further analysis is needed to determine if angle change should be considered as a safety parameter when choosing an ICL.
While there were no significant intraoperative or postoperative complications, there was one steroid-induced increase in IOP at the 1-month follow-up visit in both eyes of one patient. Over-sizing of the ICL and angle narrowing has been reported to cause an increase in IOP and glaucoma. However, the vault was $415 \mu \mathrm{m}$ in the right eye and $350 \mu \mathrm{m}$ in the left eye. Both eyes had postoperative anterior chamber angles measured by OCT of greater than $20^{\circ}$ in all meridians.

It is generally accepted that the most important safety factor for phakic IOL implantation relates to ICL sizing. For all eyes in the current study, ICL size was chosen based on VHFDU measurements imported into the Kojima formula. There was agreement in ICL size choice for 32 of the 42 eyes by the Dougherty formula and 18 of the 42 of eyes by the STAAR OCOS $^{\text {TM }}$ website calculator. An ICL one size smaller than the STAAR OCOS ${ }^{\mathrm{TM}}$ recommended lens size was used in 23 of $42(54 \%)$ eyes and two sizes smaller in 1 of $42(2.4 \%)$ of eye. 

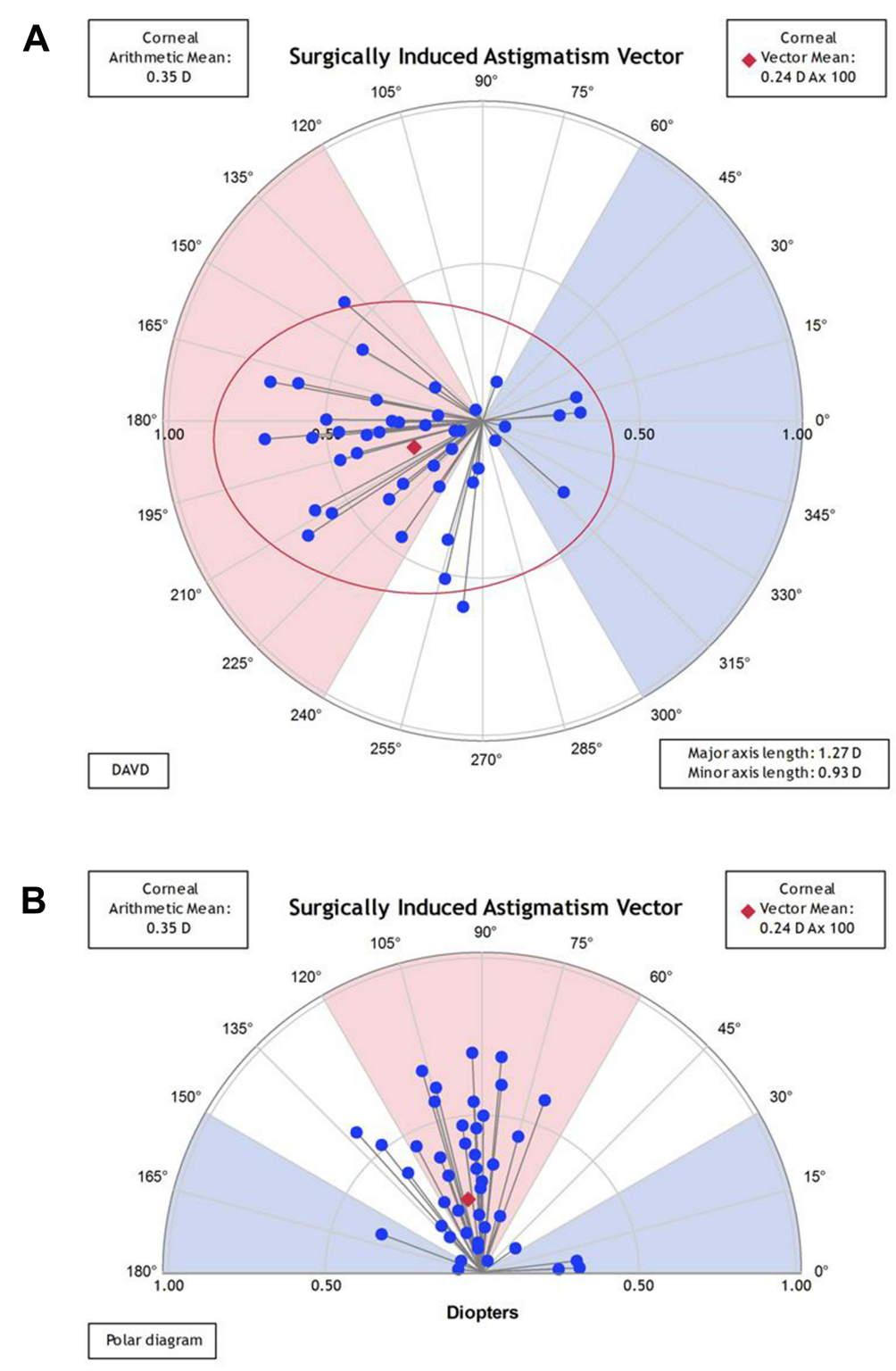

Figure 4 Surgically induced astigmatism vector (SIA) for corneal astigmatism displayed as a double angle vector diagram (DAVD) (A) and polar plot (B). The vector mean and standard deviation ellipse is shown on the DAVD. The graphs were generated using the ISRS Alpins ASSORT calculator.

The mean \pm SD lens vault in the current population was $506 \pm 233 \mu \mathrm{m}$ (range: 114 to $924 \mu \mathrm{m}, 95 \%$ confidence interval $457 \mu \mathrm{m})$. No ICL in this series of 42 consecutive eyes required early exchange due to over- or under sizing. Dougherty et al, ${ }^{11}$ using the VuMax-II high-frequency 35 MHz sector scanning probe (Sonomed Inc., Lake Success, $\mathrm{NY}$ ), reported a mean \pm SD vault of $340 \pm 174 \mu \mathrm{m}$ (range: 90 to $952 \mu \mathrm{m}, 95 \%$ confidence interval $341 \mu \mathrm{m})$ for their population of 72 eyes. Kojima et al, ${ }^{14}$ using the same VuMax-II high-frequency $35 \mathrm{MHz}$ sector scanning probe, reported a mean vault of $640 \pm 250 \mu \mathrm{m}$ (range: 190 to 1330 $\mu \mathrm{m}, 95 \%$ confidence interval 490 ) for their population of 47 eyes with a reported mean error \pm SD between actual and predicted vault of $-0.06 \pm 290 \mu \mathrm{m}(95 \%$ confidence interval $568 \mu \mathrm{m})$. The postoperative vault mean is similar to that of the Kojima report, ${ }^{14}$ which is expected, given the Kojima formula was used for sizing in the present study. Given the use of sulcus-to-sulcus sizing, it is not surprising that our vault mean was also similar to that of the Dougherty report. ${ }^{11}$ We are currently investigating the vault predictive power of other posterior chamber dimensions including the ciliary body inner diameter. A full analysis of lens sizing and the derivation of an ultrasound-based sizing formula are the subject of a future study.

The position of the lens haptics and footplates was monitored postoperatively in the present study population 
Table 6 Contrast Sensitivity

\begin{tabular}{|l|c|c|c|c|}
\hline & 3 CPD & 6 CPD & I2 CPD & I8 CPD \\
\hline Preoperative & $\begin{array}{c}1.64 \pm 0.19 \\
(1.17 \text { to } 2.08)\end{array}$ & $\begin{array}{c}1.68 \pm 0.26 \\
(0.91 \text { to } 2.14)\end{array}$ & $\begin{array}{c}1.28 \pm 0.30 \\
(0.61 \text { to } 1.69)\end{array}$ & $\begin{array}{c}0.85 \pm 0.28 \\
(0.17 \text { to } 1.40)\end{array}$ \\
\hline Postoperative* & $\begin{array}{c}1.67 \pm 0.15 \\
(1.34 \text { to } 1.93)\end{array}$ & $\begin{array}{c}1.82 \pm 0.20 \\
(1.38 \text { to } 2.29)\end{array}$ & $\begin{array}{c}1.44 \pm 0.34 \\
(0.61 \text { to } 1.99)\end{array}$ & $\begin{array}{c}1.00 \pm 0.33 \\
(0.17 \text { to } 1.55)\end{array}$ \\
\hline Change & $\begin{array}{c}0.04 \pm 0.21 \\
(-0.30 \text { to } 0.76) \\
P=0.287\end{array}$ & $\begin{array}{c}0.14 \pm 0.22 \\
(-0.30 \text { to } 0.91) \\
P<0.001\end{array}$ & $\begin{array}{c}0.14 \pm 0.31 \\
(-0.64 \text { to } 0.91)\end{array}$ & $\begin{array}{c}P=0.006 \\
(-0.64 \text { to } 0.91) \\
P=0.003\end{array}$ \\
\hline Contrast increase more than $0.25 \log$ units & $\begin{array}{c}15 \%(6) \\
5 \%(2)\end{array}$ & $\begin{array}{c}25 \%(10) \\
5 \%(2)\end{array}$ & $\begin{array}{c}30 \%(12) \\
5 \%(2)\end{array}$ & $\begin{array}{c}30 \%(12) \\
5 \%(2)\end{array}$ \\
\hline
\end{tabular}

Note: *12 months if available, 3 months otherwise.

by VHFDU with no footplate, peripheral optic edge or peripheral contacting the crystalline lens. Higher myopic power ICLs have a thinner optic center and thicker optic periphery, such that the central lens vault does not actually represent the minimum separation between the crystalline lens and the ICL. The direct monitoring of postoperative lens separation behind the physiological (non-dilated) iris can only be performed by ultrasound scanning.

Placement of the footplates anatomically may play a part on the variability of lens vault for a particular eye. In the current population just under half $(48.3 \%)$ the footplates exhibited the lowest zonule position, just under half $(49.2 \%)$ a ciliary position, and $2.5 \%$ a higher sulcus position insertion. Zhang et $\mathrm{al}^{33}$ evaluated the postoperative footplate and haptic position of the ICL in 134 eyes and found variability as well, with footplate in the ciliary sulcus $21.6 \%$, on top of the ciliary body $2.2 \%$, in the ciliary process $12.7 \%$, under the ciliary body $10.4 \%$, and in to the ciliary body in $32.1 \%$ of locations. Their analysis also showed that lenses could have a combination of two or more of these (ie one footplate in on top of the ciliary body and one footplate under the ciliary body). In the current population, 6/30 (20\%) were found to have a combination of two or more footplate positions. It may be reasonable to consider that a higher lens vault would be associated with more anterior insertion, such that if surgical techniques were to assure posterior placement, this may have an impact on the variability of lens vault.

In summary, visual outcomes of the ICL EVO and EVO+ ICL V4c models were found to be highly effective and safe in this population of eyes. The use of Artemis Insight 100 VHF digital ultrasound, combined with the Kojima lens sizing formula, produced similar results with a slightly smaller scatter in lens vault (114$924 \mu \mathrm{m})$ than demonstrated in the Kojima study (190$1330 \mu \mathrm{m}) .{ }^{14}$ The slight decrease in scatter may be attributable to the higher resolution $60 \mathrm{MHz}$ ultrasound scanning probe. A larger population study would
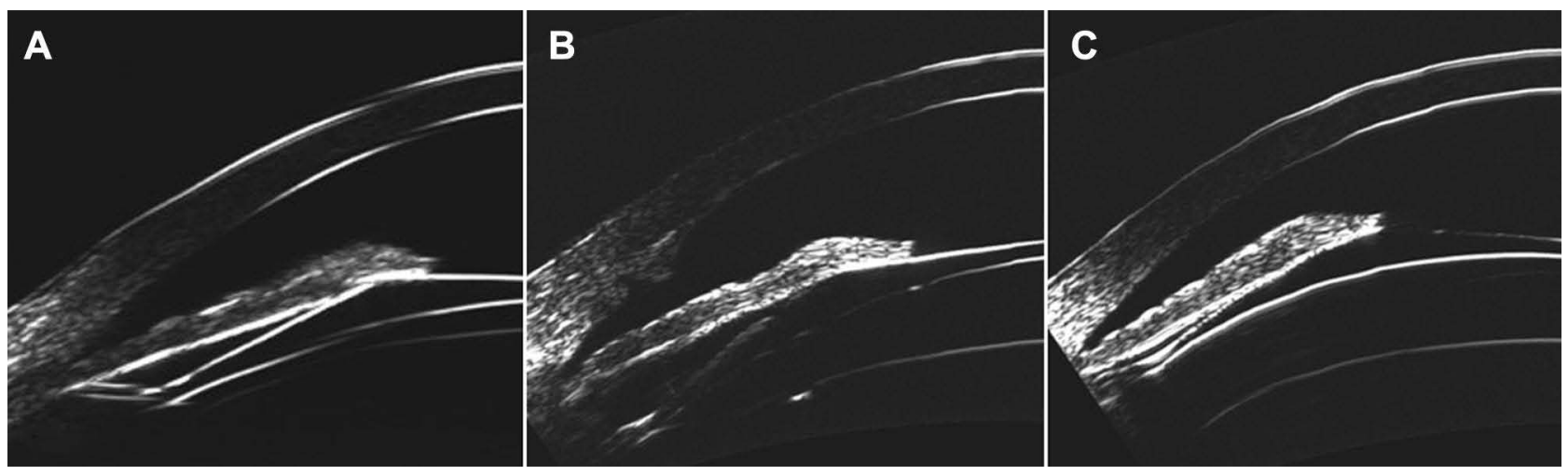

Figure 5 Ultrasound B-scan using the Insight 100 (ArcScan Inc, Golden CO) showing position of the ICL footplate. (A) shows the footplate positioned just anterior to the zonules flexing up toward the sulcus (zonule position). (B) shows the footplate inserting directly into the ciliary body (ciliary position). (C) shows the footplate entering directly into the sulcus (sulcus position) with an associated tilt to the lens. 


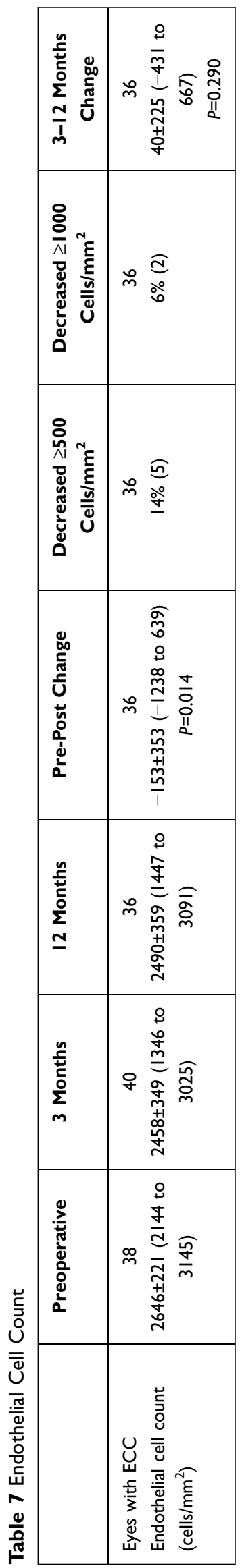

provide more information about this result. While no eye required immediate exchange due to sizing issues, the lowest and highest vault eyes may require this in the future. It is hoped that the predictability of lens vault can be further improved to avoid these outliers for longterm assurance. Further study of anatomical features of the posterior chamber that may improve the predictability of the achieved lens vault together with standardization of implantation technique to ensure consistent haptic and footplate placement should lead to improved predictability in ICL sizing and reduction or possibly elimination of sizing related complications.

\section{Funding}

This work was performed at London Vision Clinic. No external funding was received for this work.

\section{Disclosure}

Dr Reinstein is an employee of London Vision Clinic; a consultant for Carl Zeiss Meditec (Carl Zeiss Meditec AG, Jena, Germany) and has a proprietary interest in the Artemis technology (ArcScan Inc, Golden, Colorado) through patents administered by the Cornell Center for Technology Enterprise and Commercialization (CCTEC), Ithaca, New York. Dr Archer is an employee of London Vision Clinic and reports payment for writing manuscript/ employment. The authors report no other conflicts of interest in this work.

\section{References}

1. Siedlecki J, Schmelter V, Mayer WJ, et al. SMILE versus implantable collamer lens implantation for high myopia: a matched comparative study. J Refract Surg. 2020;36:150-159. doi:10.3928/1081597X20200210-02

2. Wan T, Yin H, Wu Z, Yang Y. Comparative study of implantable collamer lens implantation in treating four degrees of myopia: six-month observation of visual results, higher-order aberrations, and amplitude of accommodation. Curr Eye Res. 2019;1:1-8.

3. Choi JH, Lim DH, Nam SW, Yang CM, Chung ES, Chung TY. Tenyear clinical outcomes after implantation of a posterior chamber phakic intraocular lens for myopia. $J$ Cataract Refract Surg. 2019;45:1555-1561. doi:10.1016/j.jcrs.2019.06.015

4. Qin $\mathrm{Q}, \mathrm{Wu} \mathrm{Z}, \mathrm{Bao} \mathrm{L}$, et al. Evaluation of visual quality after EVO-ICL implantation for hypermyopia: an observational study. Medicine. 2019;98:e17677. doi:10.1097/MD.0000000000017677

5. Nakamura T, Isogai N, Kojima T, Yoshida Y, Sugiyama Y. Posterior chamber phakic intraocular lens implantation for the correction of myopia and myopic astigmatism: a retrospective 10-year follow-up study. Am $J$ Ophthalmol. 2019;206:1-10. doi:10.1016/j. ajo.2019.04.024

6. Yu Y, Zhang C, Zhu Y. Femtosecond laser assisted cataract surgery in a cataract patient with a "0 vaulted" ICL: a case report. $B M C$ Ophthalmol. 2020;20:179. doi:10.1186/s12886-020-01440-x 
7. Strungaru MH, Gonzalez J, Weisbrod DJ, Tayfour F, Buys YM. Acute angle closure following implantable collamer lens for myopia. $J$ Glaucoma. 2020;29(7):e74-e76. doi:10.1097/ IJG.0000000000001533

8. Ye C, Patel CK, Momont AC, Liu Y. Advanced pigment dispersion glaucoma secondary to phakic intraocular collamer lens implant. $\mathrm{Am}$ J Ophthalmol Case Rep. 2018;10:65-67. doi:10.1016/j.ajoc.2018.01.046

9. Karandikar S, Bhandari V, Reddy J. Outcomes of implantable collamer lens V4 and V4c for correction of high myopia - a case series. Nepal $J$ Ophthalmol. 2015;7:164-172. doi:10.3126/nepjoph. v7i2.14967

10. Surgical S. Visian ICL product information.

11. Dougherty PJ, Rivera RP, Schneider D, Lane SS, Brown D, Vukich J. Improving accuracy of phakic intraocular lens sizing using high-frequency ultrasound biomicroscopy. J Cataract Refract Surg. 2011;37:13-18. doi:10.1016/j.jcrs.2010.07.014

12. Oh J, Shin HH, Kim JH, Kim HM, Song JS. Direct measurement of the ciliary sulcus diameter by 35-megahertz ultrasound biomicroscopy. Ophthalmology. 2007;114:1685-1688. doi:10.1016/j. ophtha.2006.12.018

13. Kim KH, Shin HH, Kim HM, Song JS. Correlation between ciliary sulcus diameter measured by $35 \mathrm{MHz}$ ultrasound biomicroscopy and other ocular measurements. $J$ Cataract Refract Surg. 2008;34:632-637. doi:10.1016/j.jcrs.2007.11.034

14. Kojima T, Yokoyama S, Ito M, et al. Optimization of an implantable collamer lens sizing method using high-frequency ultrasound biomicroscopy. Am J Ophthalmol. 2012;153:632-637. doi:10.1016/ j.ajo.2011.06.031

15. Nakamura $\mathrm{T}$, Isogai $\mathrm{N}$, Kojima $\mathrm{T}$, Yoshida $\mathrm{Y}$, Sugiyama $\mathrm{Y}$. Implantable collamer lens sizing method based on swept-source anterior segment optical coherence tomography. Am J Ophthalmol. 2018;187:99-107. doi:10.1016/j.ajo.2017.12.015

16. Reinstein DZ, Archer TJ, Silverman RH, Rondeau MJ, Coleman DJ. Correlation of anterior chamber angle and ciliary sulcus diameters with white-to-white corneal diameter in high myopes using artemis VHF digital ultrasound. J Refract Surg. 2009;25:185-194.

17. Rondeau MJ, Barcsay G, Silverman RH, et al. Very high frequency ultrasound biometry of the anterior and posterior chamber diameter. $J$ Refract Surg. 2004;20:454-464. doi:10.3928/1081-597X20040901-08

18. Nakamura T, Isogai N, Kojima T, Yoshida Y, Sugiyama Y. Optimization of implantable collamer lens sizing based on swept-source anterior segment optical coherence tomography. J Cataract Refract Surg. 2020;46:742-748. doi:10.1097/j.jcrs.0000000000000134

19. Lovisolo CF, Reinstein DZ. Phakic intraocular lenses. Surv Ophthalmol. 2005;50:549-587. doi:10.1016/j.survophthal.2005.08.011

20. Reinstein DZ, Archer TJ, Silverman RH, Coleman DJ. Accuracy, repeatability, and reproducibility of Artemis very high-frequency digital ultrasound arc-scan lateral dimension measurements. $J$ Cataract Refract Surg. 2006;32:1799-1802. doi:10.1016/j.jcrs.2006.07.017
21. Reinstein DZ, Yap TE, Carp GI, Archer TJ, Gobbe M. Reproducibility of manifest refraction between surgeons and optometrists in a clinical refractive surgery practice. $J$ Cataract Refract Surg. 2014;40:450-459. doi:10.1016/j.jcrs.2013.08.053

22. Reinstein DZ, Archer TJ, Randleman JB. JRS Standard for reporting astigmatism outcomes of refractive surgery. $J$ Refract Surg. 2014;30:654-659. doi:10.3928/1081597X-20140903-01

23. Alpins N. Astigmatism analysis by the Alpins method. $J$ Cataract Refract Surg. 2001;27:31-49. doi:10.1016/S0886-3350(00)00798-7

24. Niu L, Miao H, Han T, Ding L, Wang X, Zhou X. Visual outcomes of Visian ICL implantation for high myopia in patients with shallow anterior chamber depth. BMC Ophthalmol. 2019;19:121. doi:10.1186/s12886-019-1132-z

25. Chan AT, Zauberman NA, Chan CC, Rootman DS. Outcomes after implantable collamer lens surgery in a Canadian cohort. Can J Ophthalmol. 2017;52:150-154. doi:10.1016/j.jcjo.2016.08.015

26. Yan Z, Miao H, Zhao F, et al. Two-year outcomes of visian implantable collamer lens with a central hole for correcting high myopia. J Ophthalmol. 2018;2018:8678352. doi:10.1155/2018/8678352

27. Fernandez-Vega-Cueto L, Lisa C, Esteve-Taboada JJ, Montes-Mico R, Alfonso JF. Implantable collamer lens with central hole: 3-year follow-up. Clin Ophthalmol. 2018;12:2015-2029. doi:10.2147/ OPTH.S171576

28. Miao H, Chen X, Tian M, Chen Y, Wang X, Zhou X. Refractive outcomes and optical quality after implantation of posterior chamber phakic implantable collamer lens with a central hole (ICL V4c). BMC Ophthalmol. 2018;18:141. doi:10.1186/s12886-018-0805-3

29. Edelhauser HF, Sanders DR, Azar R, Lamielle H. Corneal endothelial assessment after ICL implantation. J Cataract Refract Surg. 2004;30:576-583. doi:10.1016/j.jcrs.2003.09.047

30. Goukon H, Kamiya K, Shimizu K, Igarashi A. Comparison of corneal endothelial cell density and morphology after posterior chamber phakic intraocular lens implantation with and without a central hole. Br J Ophthalmol. 2017;101:1461-1465. doi:10.1136/bjophthalmol-2016-309363

31. Guber I, Mouvet V, Bergin C, Perritaz S, Othenin-Girard P, Majo F. Clinical outcomes and cataract formation rates in eyes 10 years after posterior phakic lens implantation for myopia. JAMA Ophthalmol. 2016;134:487-494. doi:10.1001/jamaophthalmol.2016.0078

32. Li Z, Xu Z, Wang Y, Liu Q, Chen B. Implantable collamer lens surgery in patients with primary iris and/or ciliary body cysts. $B M C$ Ophthalmol. 2018;18:287. doi:10.1186/s12886-018-0935-7

33. Zhang X, Chen X, Wang X, Yuan F, Zhou X. Analysis of intraocular positions of posterior implantable collamer lens by full-scale ultrasound biomicroscopy. BMC Ophthalmol. 2018;18:114. doi:10.1186/ s12886-018-0783-5
Clinical Ophthalmology

\section{Publish your work in this journal}

Clinical Ophthalmology is an international, peer-reviewed journal covering all subspecialties within ophthalmology. Key topics include: Optometry; Visual science; Pharmacology and drug therapy in eye diseases; Basic Sciences; Primary and Secondary eye care; Patient Safety and Quality of Care Improvements. This journal is indexed on PubMed
Central and CAS, and is the official journal of The Society of Clinical Ophthalmology (SCO). The manuscript management system is completely online and includes a very quick and fair peer-review system, which is all easy to use. Visit http://www.dovepress.com/ testimonials.php to read real quotes from published authors. 